\title{
The Structure of Dermocybin
}

\author{
BY J. H. BIRKINSHAW AND RACHEL GOURLAY \\ Department of Biochemistry, London School of Hygiene and Tropical Medicine, University of London
}

(Received 3 February 1961)

The pigments of Cortinarius (Dermocybe) sanguineus (Wulf ex Fr.) Fr. were first investigated by Kögl \& Postowsky (1925). From the dried sporophores they obtained two crystalline anthraquinone derivatives, frangula-emodin (4:5:7-trihydroxy-2-methylanthraquinone) and a new pigment, dermocybin, the structure of which was only partly determined.

The fungus is normally of infrequent occurrence, only a few scattered specimens being encountered in the woods of the Home Counties. However, in the autumn of $1946,240 \mathrm{~g}$. of fresh sporophores were easily collected in Mad Bess Wood, Ruislip, Middlesex. From these we extracted the pigments and put the material aside hoping to collect similar crops in later years and thus to accumulate sufficient material to continue the study of Kögl \& Postowsky (1925) on dermocybin. In subsequent years, however, only a few specimens of the fungus were collected until 1951, when $160 \mathrm{~g}$. of the fresh fungus was obtained. After laborious extraction and purification of the pigments a total of about $0.6 \mathrm{~g}$. of dermocybin was available. Since accumulation of enough of the material for degradative studies appeared too slow, it was decided to approach the problem of the structure of dermocybin mainly by synthetic methods. A preliminary account of this work has been presented (Birkinshaw \& Gourlay, 1961).

The properties of dermocybin as determined by Kögl \& Postowsky (1925) may be summarized as follows. Dermocybin forms red prisms or needles of m.p. 228-229 $9^{\circ}$ empirical formula $\mathrm{C}_{16} \mathrm{H}_{12} \mathrm{O}_{7}$. Zincdust micro-distillation affords $\beta$-methylanthracene. The pigment contains four hydroxyl groups that can be acetylated and one methoxyl group, the other two oxygen atoms participating in a quinone structure. Demethylation gives nordermocybin, $\mathrm{C}_{15} \mathrm{H}_{10} \mathrm{O}_{7}$, small red rhombic crystals, m.p. $289^{\circ}$. This led the authors to formulate dermocybin as a tetrahydroxymethoxy- $\beta$-methylanthraquinone. On their evidence, however, it could equally well be a trihydroxymethoxy- $\beta$-hydroxymethylanthraquinone. We were able to resolve this doubt in favour of Kögl \& Postowsky's assumption by a carbon-methyl determination. One $C$-methyl group was found to be present in the molecule.

The evidence available for the orientation of the hydroxyl groups of nordermocybin is as follows:
(1) Many fungal anthraquinones are derivatives of emodin. The occurrence of both dermocybin and emodin as metabolites of the same fungus suggests a dihydroxyemodin structure for nordermocybin, as pointed out by Kögl \& Postowsky.

(2) In studies of the visible and ultravioletabsorption spectra of polyhydroxyanthraquinones, Briggs, Nicholls \& Paterson (1952) and Birkinshaw (1955) found that the position of the major band in the visible region (group B) was considerably affected by the number of free $\alpha$-hydroxyl groups in the anthraquinone molecule. The presence of the principal absorption maximum in group $B$ at about $490 \mathrm{~m} \mu$ is indicative of three $\alpha$-hydroxyl groups [cf. islandicin, helminthosporin and catenarin (Birkinshaw, 1955)]. In emodin, with two $\alpha$ hydroxyl groups, the maximum occurs at $437 \mathrm{~m} \mu$ and in cynodontin with four $\alpha$-hydroxyl groups the principal maximum is at $558 \mathrm{~m} \mu$. In dermocybin and nordermocybin the principal maxima of group B are at $486 \mathrm{~m} \mu$. Hence it may be inferred that dermocybin and nordermocybin each have three and not more than three $\alpha$-hydroxyl groups.

(3) This assessment was confirmed by limited (short-time) acetylation (with acetic anhydride) and methylation (with diazomethane) of dermocybin and nordermocybin. Under these mild conditions only the free $\beta$-hydroxyl groups of the anthraquinone molecule react, the $\alpha$-hydroxyl groups being to some extent protected by chelation. Dermocybin, when boiled for $1 \mathrm{~min}$. with acetic anhydride, gave a monoacetyl derivative which had an absorption spectrum consistent with its still possessing three $\alpha$-hydroxyl groups, since the principal maximum in the visible spectrum was at $485 \mathrm{~m} \mu$. Further boiling $(9 \mathrm{~min}$.) of the reaction mixture produced the tetra-acetyl derivative obtained by Kögl \& Postowsky. When suspended in acetone and treated with an ethereal solution of diazomethane for $30 \mathrm{~min}$. at room temperature, dermocybin afforded a monomethyl derivative.

Nordermocybin under similar short-time conditions afforded a diacetyl and a dimethyl derivative. Further acetylation of the diacetylnordermocybin yielded a penta-acetyl derivative. The dimethyl derivative of nordermocybin was identical with the monomethyl derivative of dermocybin. These 
results indicated that dermocybin has one free $\beta$ hydroxyl group and three $\alpha$-hydroxyl groups, whereas nordermocybin has two $\beta$ - and three $\alpha$ hydroxyl groups. It is evident that one of the two $\beta$-hydroxyl groups present in nordermocybin is methylated in dermocybin.

With this information available it was decided to attempt the synthesis of nordermocybin. The possible structures derivable from emodin (structure I) by the insertion of one $\alpha$ - and one $\beta$ hydroxyl group are structures (II)-(V) since there are two vacant $\alpha$-positions ( 1 and 8 ) and two vacant $\beta$-positions (3 and 6 ) in the emodin molecule.

The first stage of the synthesis of 1:4:5:6:7-pentahydroxy-2-methylanthraquinone (III) was attained by condensing 3:4:5-trimethoxyphthalic anhydride with $m$-cresol in the presence of $\mathrm{AlCl}_{3}$ to 2-(2-hydroxy-4 - methylbenzoyl)-3:4:5-trimethoxybenzoic acid. The method of linkage was established by decarboxylation and oxidation of the product; this afforded 2:3:4-trimethoxybenzoic acid. The potential carboxyl group next to the methoxyl group of the 3:4:5-trimethoxyphthalic anhydride had evidently condensed with the $m$-cresol, the point of attachment being assumed to be ortho to the hydroxyl group. There is good precedent for this in the literature; also a para attachment at this<smiles>Cc1cc(O)c2c(c1)C(=O)C1C(O)=CC(O)C=CC1C2=O</smiles>

(I)

Emodin<smiles>COc1cccc2c(=O)c3ccccc3oc12</smiles>

(VI)<smiles>Cc1cc(O)c2c(c1)C(=O)C1C(=O)C2C(O)C(O)C(O)C1O</smiles>

(VII) stage would preclude para oxiddtion in the subsequent Elbs reaction.

As a by-product of the decarboxylation a substance of m.p. $152^{\circ}$ and empirical formula $\mathrm{C}_{16} \mathrm{H}_{14} \mathrm{O}_{4}$ with only two methoxyl groups was obtained. This must from its formula and absorption spectrum have the structure 5:6-dimethoxy-3-methylxanthone (VI) and its formation with elimination of methanol is additional evidence that the primary linkage between the two aromatic rings to form the benzoylbenzoic acid has occurred through the potential carboxyl group adjacent to a methoxyl group in the substituted phthalic anhydride. It is also confirmation that the point of attachment in the $m$-cresol ring is ortho to the hydroxyl group. The ready elimination of methanol by 2 -hydroxy2 '-methoxybenzophenones to give xanthones under very mild basic conditions was observed by McMaster, Scott \& Trippett (1960).

Oxidation of the substituted benzoylbenzoic acid with potassium persulphate (the Elbs reaction) followed by ring closure and demethylation with conc. sulphuric acid at $150^{\circ}$ gave 1:4:5:6:7-pentahydroxy-2-methylanthraquinone (III), m.p. 298$300^{\circ}$. Although the absorption spectrum of the synthetic material bears a close resemblance to that of nordermocybin the two are not identical.

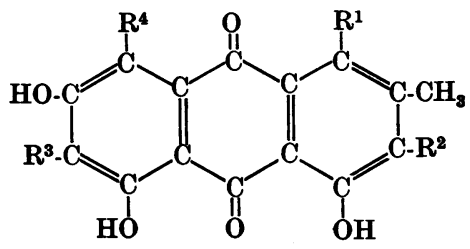

(II) $\mathrm{R}^{1}=\mathrm{R}^{2}=\mathrm{OH}, \quad \mathrm{R}^{3}=\mathrm{R}^{4}=\mathrm{H}$

(III) $\mathrm{R}^{1}=\mathrm{R}^{3}=\mathrm{OH}, \quad \mathrm{R}^{2}=\mathrm{R}^{4}=\mathrm{H}$

(IV) $\mathrm{R}^{2}=\mathrm{R}^{4}=\mathrm{OH}, \quad \mathrm{R}^{1}=\mathrm{R}^{3}=\mathrm{H}$

(V) $\mathrm{R}^{3}=\mathrm{R}^{4}=\mathrm{OH}, \quad \mathrm{R}^{1}=\mathrm{R}^{2}=\mathrm{H}$

Possible structures considered for nordermocybin.

( $\mathrm{V}$ ultimately proved correct.)

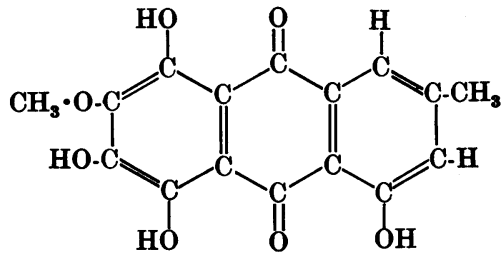

(VIII)

Alternative structures for dermocybin. 
Further, the synthetic substance affords a pure blue colour with conc. sulphuric acid in contrast with the deep amethyst given by nordermocybin.

In view of the similarity in absorption spectra the closely related compound 1:4:6:7:8-pentahydroxy-2-methylanthraquinone, although not a derivative of emodin, was synthesized by the same sequence of reactions from 3:4:5-trimethoxyphthalic anhydride and $o$-cresol. The product had m.p. 328-331 ${ }^{\circ}$ and an absorption spectrum almost identical with that of the 1:4:5:6:7-isomer (III) and hence differing slightly from that of nordermocybin. It gave a violet colour reaction with sulphuric acid.

In the final condensation in the presence of sulphuric acid in the synthesis of these two pentahydroxymethylanthraquinones, the possibility of a Hayashi (1927) rearrangement having occurred was considered, but was rejected on the following grounds. The presumed 1:4:5:6:7-pentahydroxy-2methylanthraquinone was heated with hydrogen iodide and red phosphorus. The product was oxidized to convert any anthrone or anthranol into anthraquinone. The only anthraquinone which could be isolated was emodin. Assuming no migration of hydroxyl groups during the reduction, the parent substance must be 1:4:5:6:7-pentahydroxy2-methylanthraquinone and not the 1:4:6:7:8isomer.

Of substances (II), (IV) and (V) it appeared that the 4:5:6:7:8-isomer (V) would have a spectrum most closely resembling that of the 1:4:5:6:7-isomer (III). The starting materials for the synthesis of the 4:5:6:7:8-isomer (V) were 1:2-dihydroxy-3:4-dimethoxybenzene (Baker \& Jukes, 1934) and 3methoxy-5-methylphthalic anhydride (Raistrick, Robinson \& Todd, 1933). Considerable difficulty was experienced in effecting condensation between the two moieties. Since 3-methoxy-5-methylphthalic anhydride was not readily available, preliminary experiments were carried out with the more accessible 3-hydroxyphthalic anhydride in order to determine suitable reaction conditions. A successful synthesis, although in small yield, was achieved by using a fusion mixture of aluminium chloride-sodium chloride as primary condensing agent and treating the product with conc. sulphuric acid. Demethylation occurred and 4:5:6:7:8pentahydroxyanthraquinone, m.p. $343^{\circ}$, was isolated. The absorption spectrum and colour reactions of this compound are almost identical with those given by nordermocybin. Since the introduction of the 2-methyl group would be expected to have little effect on the spectrum this evidence strongly supported structure (V) for nordermocybin. The condensation was therefore repeated with the substitution of 3-methoxy-5-methylphthalic anhydride for 3-hydroxyphthalic an- hydride, giving 4:5:6:7:8-pentahydroxy-2-methylanthraquinone (V). This compound agrees in all its properties with nordermocybin.

Since we have already shown that in dermocybin one of the $\beta$-hydroxyl groups of nordermocybin is methylated, dermocybin must be 4:5:7:8tetrahydroxy - 6 - methoxy - 2 - methylanthraquinone (VII) or 4:5:6:8-tetrahydroxy-7-methoxy-2-methylanthraquinone(VIII). No method of synthesis has so far been devised which would differentiate between the 6-and the 7-position for the methoxyl group.

A point of interest in the structure of dermocybin is the very unequal distribution of nuclear hydroxyl or potential hydroxyl groups between the two aromatic rings. One ring possesses four and the other only one oxygen function, a difference of three. In all the fungal anthraquinones of known structure, with one exception, the discrepancy between the two rings is not more than one oxygen function. The exception is boletol, to which the structure 5- (or 8-)carboxy-1:2:4-trihydroxyanthraquinone has been assigned (Kögl \& Deijs, 1935). Boletol thus shows a difference of three hydroxyl groups between the two aromatic rings. It is a product of Boletus spp. and hence like dermocybin is a metabolite of a higher fungus.

It is known that emodin, which may be regarded as the type structure for many of the fungal anthraquinones, is biosynthesized from acetate units (Gatenbeck, 1958). Since the dermocybin structure can be derived from emodin by the insertion of two further hydroxyl groups in ortho positions to those already present in the emodin molecule, together with $O$-methylation of one hydroxyl group, it appears probable that dermocybin is also biosynthesized from acetate units, the insertion of the $O$-methyl group requiring in addition a $\mathrm{C}_{1}$ unit.

\section{EXPERIMENTAL}

The $\mathrm{C}$ and $\mathrm{H}$ determinations were made by $\mathrm{Dr} A$. Schoeller. All melting points are uncorrected. The lightabsorption values of the various derivatives and synthetic products, where not given below, are recorded in Table 1 .

Isolation of dermocybin and emodin. Freshly gathered sporophores (170 g.) of Cortinarius (Dermocybe) sanguineus (Wulf ex Fr.) Fr. were exhaustively extracted with cold methanol (4.75 1.) in small portions. The filtered extract was evaporated under reduced pressure and the residue was taken up in aq. $3 \% \mathrm{NH}_{3}$ soln. $(500 \mathrm{ml}$.) and acidified with $\mathrm{HCl}$. A preliminary separation of the precipitated material into dermocybin and emodin fractions was achieved, as by Kögl \& Postowsky (1925), by dissolution in pyridine, dilution with water and filtration from the precipitate (dermocybin fraction), followed by acidification of the filtrate (emodin fraction). These fractions were, however, still far from pure and were further fractionated by a series of crystallizations from acetic acid-ethanol. The final products consisted of dermocybin 0.29 g., m.p. 225$226^{\circ}$, and emodin $0 \cdot 18$ g., m.p. 255-256 ${ }^{\circ}$. The identities of 
these products were confirmed by conversion into the fully acetylated derivatives, and, for emodin, by m.p. determinations on admixture with authentic specimens.

The properties of dermocybin were in agreement with those described by Kögl \& Postowsky (Found $C$-Me, 5.8. $\mathrm{C}_{16} \mathrm{H}_{12} \mathrm{O}_{7}$ requires $C$ - $\mathrm{Me}, 4 \cdot 75 \%$ ).

\section{Derivatives}

Monomethyldermocybin. Dermocybin (20 mg.) was mixed with acetone $(2 \mathrm{ml}$.) and an ethereal solution of diazomethane $(20 \mathrm{ml}$. from $0 \cdot 15 \mathrm{~g}$. of nitrosomethylurea) was added. The dermocybin dissolved giving a light-orange solution. After $30 \mathrm{~min}$. at room temperature the solution was filtered from a small amount of dark-red solid and the solvent was evaporated. The bright-red residue was dissolved by refluxing in the minimum amount of ethanol and the solution was chilled. The crystals (11.4 mg.) after recrystallization from ethanol afforded red needles of monomethyldermocybin, m.p. 159-160 (Found, on material dried in vacuo at $100^{\circ}: \mathrm{C}, 61 \cdot 7 ; \mathrm{H}, 4 \cdot 4 ; \mathrm{OMe}, 19 \cdot 1 . \mathrm{C}_{17} \mathrm{H}_{14} \mathrm{O}_{7}$ requires $\mathrm{C}, 61 \cdot 8$; $\mathrm{H}, 4 \cdot 3 ; 2 \mathrm{OMe}, 18 \cdot 8 \%$ ).

Monoacetyldermocybin. Dermocybin (20 mg.) was added to acetic anhydride $(1.5 \mathrm{ml}$.), and the mixture was heated to boiling under reflux, when solution occurred, and boiled for $1 \mathrm{~min}$. Bright-red needles of monoacetyldermocybin (15 mg.), m.p. 228-230 ${ }^{\circ}$, crystallized on cooling. Mixed m.p. with dermocybin (m.p. 226-228 ${ }^{\circ}$ ) gave a depression of $32^{\circ}$ (Found, on material dried in vacuo at $100^{\circ}$ : C, 60.2; $\mathrm{H}, 4 \cdot 0$; OMe, 8.7; acetyl, 10.3. $\mathrm{C}_{18} \mathrm{H}_{14} \mathrm{O}_{8}$ requires $\mathrm{C}, 60 \cdot 3$; $\mathrm{H}, 3.9$; OMe, 8.7; acetyl, $12.0 \%$ ).

Tetra-acetyldermocybin. The mother liquors from the preparation of monoacetyldermocybin were refluxed for a further $9 \mathrm{~min}$. and the orange solution was poured into water. After recrystallization of the product from methanol, rosettes of yellow needles (4.6 mg.), m.p. 179-181 ${ }^{\circ}$, were obtained. The product showed no depression in m.p. when mixed with tetra-acetyldermocybin prepared according to Kögl \& Postowsky (1925).

Dimethylnordermocybin. Nordermocybin (10.0 mg.) prepared by the method of Kögl \& Postowsky from dermocybin, was treated with an ethereal solution of diazomethane (from nitrosomethylurea, 0.075 g.). After $30 \mathrm{~min}$. at room temperature the solvent was evaporated and the residue was crystallized twice from methanol, giving bright-red needles of dimethylnordermocybin, m.p. 159$160^{\circ}$, undepressed when mixed with a sample of monomethyldermocybin. The absorption spectra of these two products were also in agreement (cf. Table 1).

Diacetylnordermocybin. Nordermocybin (40.0 mg.) was boiled in acetic anhydride $(2.5 \mathrm{ml}$.) for $1 \mathrm{~min}$. The orange needles separating on cooling were recrystallized from methanol to give needles $(14.0 \mathrm{mg}$.) of diacetylnordermocybin, m.p. $234^{\circ}$ (Found, on sample dried in vacuo at $100^{\circ}$ : C, 59.5; H, 3.6; acetyl, 20.0. $\mathrm{C}_{19} \mathrm{H}_{14} \mathrm{O}_{9}$ requires $\mathrm{C}, 59 \cdot 1$; $\mathrm{H}, 3.6 ; 2$ acetyl, $22.3 \%$ ). The acetic anhydride mother liquors were boiled for a further $9 \mathrm{~min}$. and the solution was cooled and poured into water. The precipitate crystallized from methanol in yellow needles, m.p. 196-197 ${ }^{\circ}$, undepressed when mixed with a sample of penta-acetylnordermocybin prepared as described below.

Penta-acetylnordermocybin. Nordermocybin (40 mg.) was heated at $90^{\circ}$ for $10 \mathrm{~min}$. with acetic anhydride $(5 \mathrm{ml}$.) containing conc. $\mathrm{H}_{2} \mathrm{SO}_{4}(0.1 \mathrm{ml}$.). The solution was cooled and poured into water. The yellow precipitate after two recrystallizations from methanol afforded penta-acetylnordermocybin as pale-yellow needles (21 mg.), m.p. 197$198^{\circ}$ (Found, on material dried in vacuo at $100^{\circ}$ : C, 58.7; $\mathrm{H}, 4 \cdot 0$; acetyl, $40 \cdot 0$. $\mathrm{C}_{25} \mathrm{H}_{20} \mathrm{O}_{12}$ requires $\mathrm{C}, 58 \cdot 9 ; \mathrm{H}, 4 \cdot 0$; 5 acetyl, $42 \cdot 0 \%$ ).

\section{Syntheses}

2 - (2 - Hydroxy - 4 - methylbenzoyl) - 3:4:5 - trimethoxybenzoic acid. 3:4:5-Trimethoxyphthalic anhydride (10.75 g.) was dissolved in $m$-cresol $\left(64 \mathrm{ml}\right.$.). Powdered anhydrous $\mathrm{AlCl}_{3}$ $(21.75$ g.) was added with slight cooling and the mixture kept for $2 \mathrm{hr}$. The deep-red solution was then heated at $70-75^{\circ}$ for $7 \mathrm{hr}$., cooled and poured into $2 \mathrm{~N}-\mathrm{HCl}(100 \mathrm{ml}$.) containing ice $(50 \mathrm{~g}$.). The excess of $m$-cresol was removed by steam-distillation and, after cooling, the residual solid after the supernatant had been decanted was dissolved in $\mathrm{N}-\mathrm{NaOH}(200 \mathrm{ml}$.). To precipitate the phthalein formed as by-product $\mathrm{CO}_{2}$ was passed through the solution. Acidification of the filtrate afforded red resinous material (5.6 g.), which was collected, washed with ether and recrystallized from methanol-water. 2-(2-Hydroxy-4-methylbenzoyl)3:4:5-trimethoxybenzoic acid was thus obtained as yellow crystals (3.5 g.), m.p. 205-207 ${ }^{\circ}$ (Found: C, 62.4; H, 5.1; $\mathrm{OMe}, 26 \cdot 7 . \mathrm{C}_{18} \mathrm{H}_{18} \mathrm{O}_{7}$ requires $\mathrm{C}, 62.5 ; \mathrm{H}, 5 \cdot 2 ; 3 \mathrm{OMe}$, $26.9 \%$ ).

Decarboxylation of 2-(2-hydroxy-4-methylbenzoyl)-3:4:5trimethoxybenzoic acid. The benzoylbenzoic acid $(2.5 \mathrm{~g}$.) was dissolved in quinoline $(25 \mathrm{ml}$.) and heated with copper chromite $\left(0.80 \mathrm{~g}\right.$.) at $180-190^{\circ}$ in a current of $N_{2}$. The effluent gases were bubbled through standard aq. $\mathrm{Ba}(\mathrm{OH})_{2}$. The reaction, as measured by $\mathrm{CO}_{2}$ evolution, was $70 \%$ complete in $3 \mathrm{hr}$., at which stage it was stopped. The cooled solution was poured into $2 \mathrm{~N}-\mathrm{HCl}(250 \mathrm{ml}$.) and the mixture was extracted with ether. The ether solution was washed with aq. $\mathrm{NaHCO}_{3}$ and water, dried with anhydrous $\mathrm{Na}_{2} \mathrm{SO}_{4}$, evaporated to $10 \mathrm{ml}$. and chilled. Recrystallization of the product separating afforded straw-coloured needles (0.40 g.), m.p. $152^{\circ}$, of 5:6-dimethoxy-3-methylxanthone (Found: $\mathrm{C}, 71 \cdot 1, \mathrm{H}, 5 \cdot 0 ; \mathrm{OMe}, 22 \cdot 8,23 \cdot 1 . \mathrm{C}_{16} \mathrm{H}_{14} \mathrm{O}_{4}$ requires $\mathrm{C}, 71 \cdot 1 ; \mathrm{H}, 5 \cdot 2 ; 2 \mathrm{OMe}, 23.0 \%$ ). The substance dissolved in $\mathrm{H}_{2} \mathrm{SO}_{4}$ with production of a bright-yellow colour. Lightabsorption in ethanol: $\lambda_{\max \text {. }} 239,263,305 \mathrm{~m} \mu$; $\log \epsilon 4 \cdot 66$, $4 \cdot 08,4 \cdot 19$ respectively.

The ether mother liquor from the decarboxylation afforded a gum which later crystallized. Trituration with methanol gave a solid $(0.67 \mathrm{~g}$.) which on recrystallization from methanol-water afforded colourless needles $(0.59 \mathrm{~g}$.) of 2-hydroxy-2':3':4'-trimethoxy-4-methylbenzophenone, m.p. 96-98 ${ }^{\circ}$, raised to $101^{\circ}$ on further recrystallization (Found, on sample dried in vacuo at $60^{\circ}: \mathrm{C}, 67.9 ; \mathrm{H}, 6.0 ; \mathrm{OMe}$, 30.45. $\mathrm{C}_{17} \mathrm{H}_{18} \mathrm{O}_{5}$ requires $\mathrm{C}, 67.55 ; \mathrm{H}, 6.0 ; 3 \mathrm{OMe}, 30.8 \%$ ).

Oxidation of 2-hydroxy-2':3':4'-trimethoxy-4-methylbenzophenone with potassium permanganate. The benzophenone $\left(0.59 \mathrm{~g}\right.$.) was dissolved in acetone $\left(50 \mathrm{ml}\right.$.), and $\mathrm{KMnO}_{4}$ $(2.0 \mathrm{~g}$.) was added in portions initially at room temperature, later with heating under reflux. The $\mathrm{MnO}_{2}$ was filtered off, washed with acetone, dried and suspended in $2 \mathrm{~N}-\mathrm{H}_{2} \mathrm{SO}_{4}$ $\left(20 \mathrm{ml}\right.$.). It was dissolved by passage of $\mathrm{SO}_{2}$. The solution was extracted with ether, and thus afforded a yellow oil, solidifying on rubbing with a glass rod. The product $(0.31 \mathrm{~g}$.$) , purified by sublimation in vacuo at 100^{\circ}$ and recrystallization from light petroleum (b.p. 60-80 ${ }^{\circ}$, formed colourless needles of 2:3:4-trimethoxybenzoic acid, m.p. 99-100', undepressed when mixed with an authentic sample obtained by oxidation of 2:3:4-trimethoxycinnamic 
acid (Found: $\mathrm{C}, 56 \cdot 3 ; \mathrm{H}, 5 \cdot 7 ; \mathrm{OMe}, 44 \cdot 0 . \mathrm{C}_{10} \mathrm{H}_{12} \mathrm{O}_{5}$ requires $\mathrm{C}$, $56 \cdot 6$; H, 5.7; $3 \mathrm{OMe}, 43 \cdot 9 \%$ ).

2-(2:5-Dihydroxy-4-methylbenzoyl)-3:4:5-trimethoxybenzoic acid. 2-(2-Hydroxy - 4 - methylbenzoyl)-3:4:5 - trimethoxy benzoic acid $(2.0 \mathrm{~g}$.) was dissolved in $2 \mathrm{~N}-\mathrm{NaOH}$ and $\mathrm{K}_{8} \mathrm{~S}_{2} \mathrm{O}_{8}(2.0 \mathrm{~g}$.) was added in portions during $90 \mathrm{~min}$. The brown solution after $40 \mathrm{hr}$. at room temperature was made just acid to Congo red by the addition of dil. HCl. The precipitate (unchanged starting material) was filtered off and the filtrate made strongly acid by the addition of conc. $\mathrm{HCl}$ $(35 \mathrm{ml}$.). After $72 \mathrm{hr}$. the precipitate was collected $(0.67 \mathrm{~g}$., m.p. 185-196 ${ }^{\circ}$. After recrystallization 2-(2:5-dihydroxy-4methylbenzoyl)-3:4:5-trimethoxybenzoic acid was obtained as yellow needles, m.p. 222-223 ${ }^{\circ}$ (Found: C, 59.4; H, 5.1; $\mathrm{OMe}, 25 \cdot 7 . \mathrm{C}_{18} \mathrm{H}_{18} \mathrm{O}_{8}$ requires $\mathrm{C}, 59 \cdot 7 ; \mathrm{H}, 5 \cdot 0 ; 3 \mathrm{OMe}$, $25 \cdot 7 \%$ ).

1:4:5:6:7-Pentahydroxy-2-methylanthraquinone. The above benzoylbenzoic acid $\left(1.0 \mathrm{~g}\right.$.) in conc. $\mathrm{H}_{2} \mathrm{SO}_{4}(20 \mathrm{ml}$.) was heated at $145-150^{\circ}$ for $30 \mathrm{~min}$. and at $150-155^{\circ}$ for $30 \mathrm{~min}$. to effect ring closure and demethylation. After cooling, the deep-purple solution was poured into water and the mixture was heated to $100^{\circ}$ to coagulate the dark-red precipitate. The latter was collected and crystallized from methanol, giving red needles $(0 \cdot 43 \mathrm{~g}$.) of 1:4:5:6:7-pentahydroxy-2methylanthraquinone, m.p. $298-300^{\circ}$ (Found, on sample sublimed in vacuo at $160-170^{\circ}: \mathrm{C}, 59 \cdot 4 ; \mathrm{H}, 3.6 . \mathrm{C}_{15} \mathrm{H}_{10} \mathrm{O}_{7}$ requires $\mathrm{C}, 59 \cdot 6 ; \mathrm{H}, 3 \cdot 3 \%$ ). The product gave a pure blue colour with conc. $\mathrm{H}_{2} \mathrm{SO}_{4}$.

1:4:5:6:7-Penta-acetoxy-2-methylanthraquinone. 1:4:5:6:7pentahydroxy-2-methylanthraquinone (50 mg.) was acetylated by treatment with acetic anhydride $(5 \mathrm{ml}$.) and conc. $\mathrm{H}_{2} \mathrm{SO}_{4}\left(0.1 \mathrm{ml}\right.$.) at $80^{\circ}$ for $10 \mathrm{~min}$. The solid $(80 \mathrm{mg}$., m.p. 201-204 ${ }^{\circ}$ ) obtained by dilution of the reaction mixture with water was crystallized three times from methanol affording 1:4:5:6:7-penta-acetoxy-2-methylanthraquinone as yellow rods (10.5 mg.), m.p. 215-216 ${ }^{\circ}$ (Found, on sample dried in vacuo at $100^{\circ}$ : $\mathrm{C}, 58.5 ; \mathrm{H}, 4 \cdot 2$; acetyl, 41.3. $\mathrm{C}_{25} \mathrm{H}_{20} \mathrm{O}_{12}$ requires $\mathrm{C}, 58 \cdot 5 ; \mathrm{H}, 4 \cdot 0 ; 5$ acetyl $42.0 \%$ ).

Reduction of 1:4:5:6:7-pentahydroxy-2-methylanthraquinone with hydrogen iodide. Isolation of frangula-emodin. 1:4:5:6:7Pentahydroxy-2-methylanthraquinone (0.30 g.) was reduced with $\mathrm{HI}$ and red $\mathrm{P}$ and the anthranol was oxidized with $\mathrm{CrO}_{3}$-acetic acid under the same conditions as those employed by Howard \& Raistrick (1955) for asperthecin. The crude product, purified by sublimation and crystallization from toluene, afforded orange needles $(5 \cdot 0 \mathrm{mg}$.), m.p. $255-256^{\circ}$, alone or mixed with authentic emodin, m.p. $257^{\circ}$. The light-absorption in ethanol $\left(\lambda_{\max }\right.$. 222, 252, 266, 290, $437 \mathrm{~m} \mu, \log \epsilon 4 \cdot 51,4 \cdot 22,4 \cdot 22,4 \cdot 31,4 \cdot 01$ respectively) is in agreement with that recorded for emodin (Birkinshaw, 1955). The product and authentic emodin gave an identical colour (red) with conc. $\mathrm{H}_{2} \mathrm{SO}_{4}$ and both gave the same $R_{F}$ $(0.54)$ when chromatographed on Whatman no. 1 paper with xylene solvent.

1:4:6:7:8-Pentahydroxy-2-methylanthraquinone. A solution of 3:4:5-trimethoxyphthalic anhydride $(8.0 \mathrm{~g}$.$) in$ $o$-cresol (48 ml.) was treated with powdered $\mathrm{AlCl}_{3}(16 \mathrm{~g}$.) added in portions. The reaction was carried out and the product worked up as described for the corresponding reaction with $m$-cresol, giving a brown solid (1.05 g.), m.p. 198-205 ${ }^{\circ}$. Recrystallization from methanol afforded the substituted benzoylbenzoic acid as cream needles $(0.71 \mathrm{~g}$.$) ,$ m.p. 205-207 ${ }^{\circ}$ This product $(0.71 \mathrm{~g}$.) was oxidized by the Elbs method (alkaline $\mathrm{K}_{2} \mathrm{~S}_{2} \mathrm{O}_{8}$ ) as described earlier for the isomer. The brown solid $(0 \cdot 18$ g. $)$, m.p. $221-225^{\circ}$, thus obtained was, without further purification, heated with conc. $\mathrm{H}_{2} \mathrm{SO}_{4}\left(3.6 \mathrm{ml}\right.$.) at $145-150^{\circ}$ for $25 \mathrm{~min}$. and at 150 $155^{\circ}$ for $25 \mathrm{~min}$. The cooled solution was poured into water, the temperature of which was raised to $100^{\circ}$. The amorphous red precipitate was collected and crystallized from methanol, giving red cubes (80 mg.) of 1:4:6:7:8-pentahydroxy-2-methylanthraquinone, m.p. 325-330 . Sublimation in vacuo at $180^{\circ}$ afforded light-red needles, m.p. 328$331^{\circ}$ (Found: $\mathrm{C}, 59 \cdot 8 ; \mathrm{H}, 3 \cdot 5 . \mathrm{C}_{15} \mathrm{H}_{10} \mathrm{O}_{7}$ requires $\mathrm{C}, 59 \cdot 6$; $\mathrm{H}, 3.3 \%)$. The product gave a violet colour with conc. $\mathrm{H}_{2} \mathrm{SO}_{4}$.

1:4:6:7:8-Penta-acetoxy-2-methylanthraquinone. The above anthraquinone $(44 \mathrm{mg}$.) in acetic anhydride $(1.5 \mathrm{ml}$.) containing conc. $\mathrm{H}_{2} \mathrm{SO}_{4}(0.03 \mathrm{ml}$. $)$ was heated at $70-75^{\circ}$ for 10 min. Straw-coloured needles separated on cooling and were collected. Three recrystallizations from methanol gave 1:4:6:7:8-penta-acetoxy-2-methylanthraquinone as lightyellow needles, m.p. 238-240 (Found, on sample dried in vacuo at $100^{\circ}$ : $\mathrm{C}, 58 \cdot 4 ; \mathrm{H}, 4 \cdot 0$; acetyl, 41.0. $\mathrm{C}_{25} \mathrm{H}_{20} \mathrm{O}_{12}$ requires $\mathrm{C}, 58 \cdot 5 ; \mathrm{H}, 4 \cdot 0 ; 5$ acetyl, $42 \cdot 0 \%$ ).

4:5:6:7:8-Pentahydroxyanthraquinone. 3-Hydroxyphthalic anhydride $(0.97 \mathrm{~g}$.) was mixed to a paste with $1: 2$ dihydroxy-3:4-dimethoxybenzene $(1.0 \mathrm{~g}$.) and added in portions to a fused mixture of $\mathrm{AlCl}_{3}(8 \cdot 14 \mathrm{~g}$.) and $\mathrm{NaCl}$ (1.62 g.) at $120-130^{\circ}$ (oil bath). The temperature was raised to $165^{\circ}$ and held for $30 \mathrm{~min}$., then to $180^{\circ}$ for $15 \mathrm{~min}$. The dark-brown mixture, after cooling, was poured into dil. HCl containing ice. The mixture was boiled and then extracted with ethyl acetate. The brown residue obtained after removal of solvent was heated with conc. $\mathrm{H}_{2} \mathrm{SO}_{4}$ $\left(5.0 \mathrm{ml}\right.$.) at $145-150^{\circ}$ for $20 \mathrm{~min}$. and at $150-155^{\circ}$ for $20 \mathrm{~min}$., cooled, and poured into water. The product was extracted with ethyl acetate. Removal of solvent by distillation in vacuo afforded a red residue $(120 \mathrm{mg}$.) which was acetylated by heating at $80-90^{\circ}$ for $10 \mathrm{~min}$. with acetic anhydride $\left(5 \cdot 0 \mathrm{ml}\right.$.) and conc. $\mathrm{H}_{2} \mathrm{SO}_{4}(0.1 \mathrm{ml}$.). The yellow-brown acetate obtained after dilution with water crystallized from methanol in yellow needles $(32 \mathrm{mg}$.$) ,$ m.p. $184-185^{\circ}$, raised to $196^{\circ}$ by recrystallization. The acetate (22 mg.) was hydrolysed by refluxing for $75 \mathrm{~min}$. with methanol ( $2 \mathrm{ml}$.) containing $3 \%(\mathrm{v} / \mathrm{v})$ of conc. $\mathrm{H}_{2} \mathrm{SO}_{4}$. The product obtained on cooling consisted of orange-red plates (13 mg.) of 4:5:6:7:8-pentahydroxyanthraquinone, m.p. $343^{\circ}$ (sublimation from $285^{\circ}$ ) (Found, on material dried in vacuo at $100^{\circ}: \mathrm{C}, 58 \cdot 2 ; \mathrm{H}, 3.0 . \mathrm{C}_{14} \mathrm{H}_{8} \mathrm{O}_{7}$ requires $\mathrm{C}$, $58.3 ; \mathrm{H}, 2.8 \%$ ). The colour with conc. $\mathrm{H}_{2} \mathrm{SO}_{4}$ was deep amethyst, identical with that given by nordermocybin.

4:5:6:7:8-Penta-acetoxyanthraquinone. The pentahydroxyanthraquinone $(20 \mathrm{mg}$.) was reconverted into the acetate, giving a pale-yellow solid (32.7 mg.), m.p. 182-185'. Two crystallizations from methanol gave 4:5:6:7:8-penta-acetoxyanthraquinone as yellow rods (24 mg.), m.p. 198-199 ${ }^{\circ}$ (Found, on sample dried in vacuo at $100^{\circ}: \mathrm{C}, 58 \cdot 1$; H, 3.7; acetyl 43.8. $\mathrm{C}_{24} \mathrm{H}_{18} \mathrm{O}_{12}$ requires $\mathrm{C}, 57 \cdot 8 ; \mathrm{H}, 3 \cdot 6 ; 5$ acetyl, $43 \cdot 3 \%$ ).

4:5:6:7:8-Pentahydroxy-2-methylanthraquinone. 3-Methoxy-5-methylphthalic anhydride $(0.47 \mathrm{~g}$.) was mixed with 1:2-dihydroxy-3:4-dimethoxybenzene $(0.50 \mathrm{~g}$.) and heated to $120^{\circ}$. Most of the anhydride dissolved in the phenol. $\mathrm{AlCl}_{3}(4 \cdot 0$ g.) and $\mathrm{NaCl}(0 \cdot 4 \mathrm{~g}$.) were ground up quickly and added to the solution with constant stirring. The temperature was raised to $200^{\circ}$ and maintained for $20 \mathrm{~min}$. The dark-brown powdery mixture was allowed to cool and 
Table 1. Light-absorption spectra of several polyhydroxyanthraquinones in ethanol

Substance
Dermocybin
Dermocybin monoacetate
Nordermocybin
Nordermocybin dimethyl ether
Nordermocybin diacetate
1:4:5:6:7-Pentahydroxy-2-methyl-
anthraquinone
1:4:6:7:8-Pentahydroxy-2-methyl-
anthraquinone
4:5:6:7:8-Pentahydroxyanthraquinone
4:5:6:7:8-Pentahydroxy-2-methyl-
anthraquinone

\begin{tabular}{ccccccc}
\multicolumn{7}{c}{$\lambda_{\max .}(\mathbf{m} \mu)$ with log $\epsilon$ in parentheses } \\
\hline $219 \cdot 5$ & $262 \cdot 5$ & 279 & 459 & 486 & 521 & - \\
$(4 \cdot 43)$ & $(4 \cdot 38)$ & $(4 \cdot 33)$ & $(4 \cdot 07)$ & $(4 \cdot 14)$ & $(4 \cdot 00)$ & \\
223 & 262 & 307 & $462-464$ & 487 & $505-508, * 520$ & - \\
$(4 \cdot 42)$ & $(4 \cdot 50)$ & $(3 \cdot 98)$ & $(4 \cdot 10)$ & $(4 \cdot 21)$ & $(4 \cdot 06)(4 \cdot 04)$ & \\
230 & 259 & 304 & - & 485 & - & $560-570$ \\
$(4 \cdot 44)$ & $(4 \cdot 50)$ & $(4 \cdot 04)$ & & $(4 \cdot 12)$ & & $(3 \cdot 00)$ \\
219 & 266 & 289 & 455 & 486 & 520 & - \\
$(4 \cdot 49)$ & $(4 \cdot 26)$ & $(4 \cdot 37)$ & $(4 \cdot 03)$ & $(4 \cdot 10)$ & $(3 \cdot 99)$ & \\
223 & 262 & 307 & $462-466$ & 487 & $505-510, * 520$ & - \\
$(4 \cdot 45)$ & $(4 \cdot 49)$ & $(3 \cdot 94)$ & $(4 \cdot 08)$ & $(4 \cdot 19)$ & $(4 \cdot 05)(4 \cdot 04)$ & \\
221 & 261 & $285-289 *$ & $460-468 *$ & 487 & $510-520^{*}$ & - \\
$(4 \cdot 42)$ & $(4 \cdot 36)$ & $(4 \cdot 18)$ & $(4 \cdot 01)$ & $(4 \cdot 07)$ & $(3 \cdot 95)$ & \\
222 & - & 291 & - & 486 & 512 & - \\
$(4 \cdot 40)$ & & $(4 \cdot 39)$ & & $(4 \cdot 16)$ & $(4 \cdot 09)$ & \\
223 & - & 291 & - & 486 & 508 & - \\
$(4 \cdot 43)$ & & $(4 \cdot 42)$ & & $(4 \cdot 18)$ & $(4 \cdot 10)$ & \\
217 & 263 & 290 & 460 & 486 & $520-525 *$ & - \\
$(4 \cdot 50)$ & $(4 \cdot 26)$ & $(4 \cdot 36)$ & $(4 \cdot 09)$ & $(4 \cdot 19)$ & $(4 \cdot 03)$ & \\
$219 \cdot 5$ & 266 & 289 & 455 & 485 & 520 & - \\
$(4 \cdot 48)$ & $(4 \cdot 26)$ & $(4 \cdot 33)$ & $(3 \cdot 99)$ & $(4 \cdot 11)$ & $(3 \cdot 95)$ & \\
& & & & & &
\end{tabular}

added to iced dil. HCl. The solution was heated to boiling and extracted with ethyl acetate. The residual gum from the ethyl acetate was treated with conc. $\mathrm{H}_{2} \mathrm{SO}_{4}(6 \cdot 0 \mathrm{ml}$.) for $20 \mathrm{~min}$. at $145-150^{\circ}$ and for $20 \mathrm{~min}$. at $150-155^{\circ}$. The product obtained by pouring the solution into water was extracted with ethyl acetate and obtained as a red-brown solid (85 mg.) which was purified through acetylation and hydrolysis. Reacetylation and crystallization from methanol afforded the purified acetate as yellow needles (11.6 mg.), m.p. 195-196 ${ }^{\circ}$. No depression in m.p. was observed when this acetate was mixed with a sample of nordermocybin penta-acetate. The purified acetate (11.6 mg.) was hydrolysed by heating with methanol $\left(1.5 \mathrm{ml}\right.$.) and conc. $\mathrm{H}_{2} \mathrm{SO}_{4}(3 \%, \nabla / v)$. The product crystallized on cooling as bright-red needles (6.2 mg.) of 4:5:6:7:8pentahydroxy-2-methylanthraquinone, m.p. 284-286 ${ }^{\circ}$, undepressed when mixed with nordermocybin (Found, on sample dried in vacuo at $100^{\circ}: \mathrm{C}, 59 \cdot 5 ; \mathrm{H}, 3 \cdot 6 . \mathrm{C}_{15} \mathrm{H}_{10} \mathrm{O}_{7}$ requires $\mathrm{C}, 59 \cdot 6 ; \mathrm{H}, 3.3 \%$ ). The product gives a deepamethyst colour with conc. $\mathrm{H}_{2} \mathrm{SO}_{4}$, identical with that given by nordermocybin. The light-absorption of the synthetic product and nordermocybin is also identical (see Table 1).

\section{SUMMARY}

1. Dermocybin, a metabolite of the fungus Cortinarius sanguineus, is a tetrahydroxymethoxy2-methylanthraquinone in which three of the hydroxyl groups are in the $\alpha$-position and one hydroxyl and the methoxyl group are in the $\beta$ position in the anthraquinone nucleus.

2. To elucidate the structure of nordermocybin, 1:4:5:6:7-pentahydroxy-2-methyl-, 1:4:6:7:8-penta- hydroxy-2-methyl-, 4:5:6:7:8-pentahydroxy- and 4:5:6:7:8 - pentahydroxy - 2 - methyl - anthraquinone were synthesized.

3. Nordermocybin is identical with $4: 5: 6: 7: 8$ pentahydroxy-2-methylanthraquinone.

4. Dermocybin has therefore the structure 4:5:6:8 - tetrahydroxy - 7-methoxy - 2 -methylanthraquinone or 4:5:7:8-tetrahydroxy-6-methoxy-2 methylanthraquinone.

We have to thank Dr E. N. Morgan and Dr P. Chaplen for the isolation of pure specimens of dermocybin and emodin from the fungus. We are also indebted to the Central Research Fund of London University for a grant for the purchase of the spectrophotometer used in this work.

\section{REFERENCES}

Baker, W. \& Jukes, E. H. J. (1934). J. chem. Soc. p. 1681. Birkinshaw, J. H. (1955). Biochem. J. 59, 485.

Birkinshaw, J. H. \& Gourlay, R. (1961). Biochem. J. 79, 3 P.

Briggs, L. H., Nicholls, G. A. \& Paterson, R. M. L. (1952). J. chem. Soc. p. 1718.

Gatenbeck, S. (1958). Acta chem. scand. 12, 1211.

Hayashi, M. (1927). J. chem. Soc. p. 2516.

Howard, B. H. \& Raistrick, H. (1955). Biochem. J. 59, 482. Kögl, F. \& Deijs, W. B. (1935). Liebigs Ann. 515, 10.

Kögl, F. \& Postowsky, J. J. (1925). Liebigs Ann. 444, 1.

McMaster, W. J., Scott, A. I. \& Trippett, S. (1960). J. chem. Soc. p. 4628.

Raistrick, H., Robinson, R. \& Todd, A. R. (1933). J. chem. Soc. p. 489. 